\title{
ESTUDO DA RELAÇÃO DOS FATORES POTENCIALMENTE EROSIVOS DE 08 MARCAS DE CERVEJAS NACIONAIS
}

Stella Miryan PARZIANELLO, Thiago Maciel MUNARETTO, Karine Fátima LYKO, Elaine Machado BENELLI, Fabiana Marques STAUT

Há uma grande preocupação quanto aos efeitos erosivos decorrentes do consumo desordenado de bebidas que apresentam baixo $\mathrm{pH}$. Nos últimos três anos, foram publicados nos anais da Reunião da Sociedade Brasileira de Pesquisa Odontológica cerca de 25 estudos sobre o potencial erosivo de diversas bebidas, dentre eles, apenas 08 com bebidas alcoólicas. Os estudos concluíram que as bebidas ácidas são potencialmente erosivas aos tecidos dentários duros, porém este não é o único fator determinante para a ocorrência de lesões erosivas. A proposta deste trabalho foi mensurar o $\mathrm{pH}$ de 08 diferentes marcas de cervejas nacionais disponíveis no mercado e indicar os valores correspondentes ao teor alcoólico. Três lotes diferentes de cada marca foram analisados através de um pHmetro de bancada e os valores de teor alcoólico observados no rótulo do produto. $\mathrm{O}$ menor $\mathrm{pH}$ foi da marca $\mathrm{Sol}{ }^{\circledR}$ (média $=\mathrm{pH} 4,08$ ) e o maior da Schincariol® (média=pH4,30). O teor alcoólico variou entre 4,5\% (Kaiser®) e 5\% (Bohemia®). Não houve significância estatística entre as marcas estudadas, nem entre os lotes. As cervejas analisadas neste estudo apresentaram $\mathrm{pH}$ abaixo do crítico ( $\mathrm{ph}<5,5)$ podendo ser consideradas potencialmente erosivas aos tecidos dentais. Os resultados podem servir como uma orientação complementar durante o aconselhamento dietético preventivo.

Palavras-chave: Erosão dentária, bebidas alcoólicas, pH. 